\title{
A VISÃO ETNOGRÁFICA DE BRUNO LATOUR DA CIÊNCIA MODERNA E A ANTROPOLOGIA SIMÉTRICA
}

Neusa Teresinha Massoni neusa.massoni@ufrgs.br 0000-0002-1145-111X Universidade Federal do Rio Grande do Sul-UFRGS-Porto Alegre, Rio Grande do Sul, Brasil

Marco Antonio Moreira moreira@if.ufrgs.br 0000-0003-2989-619X Universidade Federal do Rio Grande do Sul-UFRGS-Porto Alegre, Rio Grande do Sul, Brasil

\section{RESUMO}

O objetivo deste texto é apresentar ideias de Bruno Latour sobre a natureza da ciência a partir de sua imersão em um laboratório científico de vanguarda, à época, oportunidade em que investigou, com métodos etnográficos, a ciência na sua prática. Com isso, distanciou-se da epistemologia tradicional, a qual critica, entendendo-a muito mais preocupada com a distinção entre enunciados científicos e não científicos e com o valor e objetividade de distintos enunciados. Com seu estudo, mostrou que as condições de produção não são independentes dos produtos da ciência; que os "seres", propriedades e objetos que a ciência pode produzir com extrema competência, e que tanto modificaram e continuam modificando a vida da sociedade moderna, precisam ser socializados e percebidos sob novas bases e novas perspectivas.

PALAVRAS-CHAVE: etnografia da ciência; Bruno Latour, vida de laboratório, antropologia simétrica. 


\section{INTRODUÇÃO}

Bruno Latour, nascido em 1947 na França, é sociólogo, doutor em Filosofia e fundador dos chamados estudos etnográficos, ou antropológicos, da ciência. Foi professor no Institut d'Études Politiques de Paris, ensinou na École Nationale Supérieure des Mines de Paris e na Universidade da Califórnia, em San Diego, entre outras. É autor de uma pesquisa etnográfica, isto é, de bases antropológicas, que buscou compreender a natureza da ciência a partir do interior de um espaço muito particular para seu desenvolvimento: o laboratório. Esse estudo resultou em uma obra que ganhou notoriedade intitulada $A$ Vida de Laboratório: a produção dos fatos científicos (1997, 1a edição é de 1979). Depois, voltou seu olhar para os efeitos da ciência nas culturas - a relação entre o discurso científico e a sociedade, a indústria, a técnica e escreveu Jamais fomos modernos (LATOUR, 1994). Neste estudo, ele enfoca a modernidade que, segundo sua análise, teria sido o argumento usado para distinguir o Ocidente dos povos que foram considerados primitivos, ou seja, não ocidentais, não modernos. Essa distinção, defende ele, precisa ser reinterpretada se quisermos compreender os conflitos da sociedade contemporânea, bem como melhor situar o papel do discurso científico, que ele considera como sendo o mais importante discurso ocidental.

Como ele próprio narra (LATOUR, 2008), após concluir o curso de Filosofia foi através do serviço militar que descobriu e converteu-se aos métodos empíricos de campo, tomados emprestados dos antropólogos, e iniciou um programa de pesquisa que ele denominou antropologia simétrica. A questão principal, segundo Latour, é que a antropologia convencional estuda o coração de outras culturas (técnica, religião, economia, costumes exóticos, bruxarias), por exemplo, as africanas, mas estranhamente trata de maneira diferencial a nossa cultura ocidental, isto é, limita-se a tratar as margens desta (e. g., artes e tradições populares, festas, representações simbólicas dos camponeses, guetos). Mas o "coração" de nossa cultura ocidental não é (não era) objeto de estudos antropológicos (a engenharia dos metrôs, a indústria, a ciência, a técnica). Nisso reside, afirma ele, a assimetria.

No máximo, segundo a visão de Latour, tratam da medicina, reputada como uma ciência "mole"1. Mesmo neste caso, contudo, eles estudam de preferência a etnomedicina ou as medicinas paralelas (LATOUR; WOOLGAR, 1997, p. 19). Para ele, até a década de setenta podia se contar nos dedos de uma mão as obras que faziam análises criteriosas e históricas da ciência e ainda assim eram escritas pelos próprios cientistas (e. g., WATSON, 1968; FLECK, 1979). Alguns sociólogos começaram a publicar trabalhos importantes sobre as instituições científicas nas décadas de 60/70, ele cita Lemaine e Matalon (1969) e Bourdieu (1976), mas o faziam através de entrevistas e questionários; não iam a campo e interessavamse muito mais pelas lutas de poder entre cientistas e menos com os "objetos" com os quais os cientistas trabalham.

\footnotetext{
Păgina $62{ }^{1}$ A expressão "ciência mole" não é usada por Latour em sentido ofensivo, mas em oposição às ciências da natureza consideradas, em geral, ciências "duras".
} 


\section{A vanguarda dos estudos antropológico/etnográficos}

Latour, contrariamente, interessou-se por uma epistemologia aberta (densa e artesanal), com os objetos com os quais os cientistas trabalham, com a prática de construção de algoritmos e da escrita de equações, mas também com as máquinas, os instrumentos, as ideologias, a infância dos cientistas, os pequenos detalhes (e. g., de Pasteur se descreverão contemporaneamente o seu laboratório, o que faz, os seus micróbios, os seus instrumentos... [LATOUR, 2008, p. 19]). Sua crítica à epistemologia tradicional centra-se no fato de que os epistemólogos buscam, em geral, uma explicação das ciências baseada na noção de que a razão triunfa sempre sobre as condições de produção do conhecimento e acabam eliminando-as, embora considere importante o estudo histórico das ciências, como na obra de Kuhn (2003), por exemplo.

Visando recolocar antigas questões, argumenta ele, deu início a um programa de pesquisa que denominou antropologia simétrica. A ideia central é analisar com os mesmos métodos e princípios - aqueles da etnografia ou antropologia - tanto a nossa cultura moderna quanto as outras culturas, tanto as margens quanto o "coração" das sociedades. Assim, argumenta que é preciso desvelar "o coração" dos diferentes lugares em que se produz aquelas que são consideradas as "verdades" mais fundamentais para a sociedade moderna: as ciências. Como ele próprio narra, desejou fazer esse estudo sem se basear no que os cientistas e pesquisadores dizem de si mesmos, mas os tomando como o que os antropólogos chamam de "informantes" e através de imersão no laboratório estabelecer uma relação mais direta e completa com os pesquisadores, e fazer um estudo empírico detalhado da prática científica. De certa forma, Latour buscou seguir um conselho atribuído a Einstein (PÉREZ TAMAYO, 2003, p. 42): se querem averiguar algo sobre os métodos que usam os físicos teóricos, aconselhoos a observarem rigorosamente um princípio: não escutem o que eles dizem, mas fixem sua atenção no que eles fazem.

Nesse sentido, Latour não investe contra a ciência. Seu ponto é que as ciências oferecem muito mais do que a distinção entre enunciados científicos e não científicos. As ciências constroem novos "seres" e colocam os humanos em contato com esses "seres" (partículas elementares, micróbios, transistores) que não existiriam se não houvesse a pesquisa científica. Defende que enquanto as ciências não foram analisadas em suas práticas constituíram-se na arma da modernização. Voltaremos a essas questões mais adiante neste texto.

Para conseguir seu intento, afirma ele, assumiu o seguinte postulado:

Se se quer compreender a sociedade contemporânea, é necessário estudar a sua principal fonte de verdade, a ciência. O que aconteceria se aplicássemos métodos antropológicos e etnográficos à produção científica? (LATOUR, 2008, p. 8).

Assim, após trabalhar na África e na América realizando estudos antropológicos, foi convidado a passar dois anos (entre 1975 e 1977) em um laboratório de neuroendocrinologia do Instituto Salk, na Califórnia, imerso em um grupo de cientistas chefiados por Roger Guillemin enquanto trabalhavam em um projeto que culminou em um Prêmio Nobel. Sua participação na vida do laboratório foi base para a redação do livro, em colaboração com o sociólogo Steve Woolgar, que tomou a descrição etnográficados processos circunstanciais 
de interação no laboratório como analiticamente relevante para a análise sociológica de prática cientifica (KROPF; FERREIRA, 1998, p. 597). Ali Latour pôde fazer um escrutínio das ações, das técnicas, da aparelhagem, das relações pessoais e profissionais, da circulação e origem de ideias, da escrita de artigos, entre outros aspectos da produção científica. O resultado, como já dito, foi o livro A Vida de Laboratório (1997), que investe contra o ideal de uma ciência pura, como afirma Stengers (2002).

No laboratório, à época um moderno laboratório de neuroendocrinologia, Latour colocou em prática o que ele chamou de métodos antropológicos clássicos, ocupou-se de tudo o que estava no laboratório: da disposição espacial às relações familiares dos pesquisadores; das metodologias empregadas para sintetizar (peptídeos) à descrição dos experimentos e testes, das reuniões e discussões de grupo à construção de relatórios, rascunhos e por fim artigos.

A narrativa detalhada mesclando anotações em diários de campo com a análise de entrevistas com os membros do grupo de pesquisa fez surgir uma nova visão da produção científica ${ }^{2}$ como até então não se tinha conhecimento.

Esse foi considerado o primeiro estudo etnográfico da ciência e teve o mérito de mostrar que a etnografia (baseada no uso de métodos antropológicos) é uma técnica útil para compreender as nuanças da produção do conhecimento científico e para verificar que, como afirma Latour, os fatos científicos não são descobertos, mas socialmente construídos. Observando o ambiente físico do laboratório, o trabalho e os movimentos dos pesquisadores, as relações e associações com outros laboratórios, o funcionamento e o papel da instrumentação (que torna possível o fenômeno, a existência de novos "seres" e novas propriedades), o processo de produção de afirmações (a inscrição literária), as relações estratégicas e políticas do chefe do laboratório com outras instâncias e com outros grupos de pesquisa, as questões éticas e morais (ou mesmo a falta delas) permitiram a Latour lançar sobre a vida daquele laboratório um olhar diferenciado e também compreender melhor como e porque os enunciados da ciência não são dissociáveis das suas condições de produção.

Para ele, a etnografia da ciência tem também a vantagem, e o risco, de abordar a questão da multiplicidade de mundos, de ver a ciência não apenas como produtora de enunciados científicos, pretensamente embasados na objetividade e racionalidade científica. A ciência, defende ele, oferece algo de mais fundamental: coloca os humanos em contato com "seres" que, se não fosse ela [a ciência], não fariam parte do nosso mundo (e. g., moléculas, sensores). Não se pode pensar em economia sem os economistas, em pedagogia sem os pedagogos, em física sem os físicos (LATOUR, 2008, p. 27).

${ }^{2}$ Edgar Lyra (2010) ao falar da importância da obra de Karl Popper destaca que ele colocou em discussão não apenas os métodos científicos modernos criticando as teorias epistemológicas de sua época, mas também foi um pensador político, embora seu posicionamento político tenha sido menos original do que o de seus contemporâneos (e.g. Bertrand Russell). Mas Popper ocupa um lugar central no debate filosófico que discutiu a fundamentação da tese do "cientificamente comprovado", nos anos 1920 na Europa, a partir do momento que se percebeu que a ciência ocupava um lugar cada vez mais destacado como nossa principal forma de construção da verdade. Popper não acreditava que o ser humano, quer fosse F pela ciência ou por outra via, pudesse chegar à verdade e ter a certeza de tê-lo feito. Ele achava que teses que reivindicavam para si o status de verdade definitiva eram teses rechaçadas, dado que nosso conhecimento é transitório e conjectural. 
Esse estudo, para Lenoir (2003), embora possa ser considerado um microestudo em que o contexto é limitado à cultura do laboratório, compõe um programa de trabalho caracterizado como programa forte do construtivismo social em ciência ${ }^{3}$ por enfocar o contexto da produção do conhecimento científico.

\title{
Vida de laboratório
}

Para tentar acompanhar como a obra (LATOUR; WOOLGAR, 1997) consegue desvelar as complexas relações da vida do laboratório e as diversas e intrincadas etapas de construção de um fato científico, as regras e os objetivos que movem os cientistas e a dependência que seu trabalho tem do instrumental e da técnica, bem como a importância das relações cooperativas, às vezes competitivas, entre os pesquisadores de uma mesma área, a luta por financiamento e reconhecimento, a origem, às vezes arbitrária, das ideias e o poder de persuasão do discurso dos cientistas, nada melhor do que nos valermos das próprias palavras de Latour, enquanto observador imerso no laboratório, como já foi dito.

Sobre o trabalho dos pesquisadores com quem conviveu e a origem dos recursos que mantinham o laboratório, ele escreve:

\begin{abstract}
Dir-se-ia que o trabalho de todos eles é guiado por um campo invisível, ou que eles formam um quebra-cabeça quase terminado e que talvez chegue a se completar ainda hoje. Tanto os edifícios em que essas pessoas trabalham quanto as carreiras que seguem estão salvaguardados pelo Instituto Salk. O dinheiro do contribuinte norte-americano chega todo mês, via National Institute of Health ou National Science Foundation. Às vezes há coletas privadas, organizadas para garantir o trabalho dos pesquisadores. As futuras conferências e exposições são ansiosamente aguardadas por todos. A cada dez minutos o telefone toca (...). (ibid., p. 11).
\end{abstract}

Sobre as instalações do laboratório de Fisiologia, ele descreve:

Fizeram-me percorrer o laboratório. À direita, na fisiologia, só há mulheres de jaleco branco, e elas não param de trabalhar. Só ha um homem na fisiologia (...). É o criador e matador de ratos brancos. Há milhares de ratos, ratos puros, segundo me dizem, incestuosos há dezenas de gerações. É na guilhotina que rolam suas cabeças. Mãos hábeis quebram crânios, extirpam o cérebro, separam cuidadosamente as hipófises (...). Eu não sabia mais se esse real era racional e se essas hecatombes tinham como objetivo atingir o melhor dos mundos científicos possíveis. (ibid., p. 15).

Sobre o trabalho no laboratório de Química (anexo ao de Fisiologia), escreve:

(...) pelo que pude compreender, havia uma molécula que os químicos ainda não haviam obtido. Ela nunca estava suficientemente pura. À medida que mencionavam a pureza, a excitação aumentava. Os ascetas tornavam-se caçadores. Falava-se ao telefone, de Tóquio a Oxford. (...). Cristalizada, a molécula aguardava. Extraída do cérebro onde reagia com milhares de

${ }^{3}$ David Bloor (1981) chamava de "programa fraco" a ideia de que era suficiente cercar a "dimensão cognitiva" das ciências com uns poucos "fatores sociais" para ter o direito de ser chamado de historiador e sociólogo. O programa forte f exigia, ao contrário, que se investisse no núcleo, no conteúdo das ciências, independentemente do método utilizado para tal. 
companheiras, abandonada pelas proteínas que a protegiam e que não puderam resistir à tripsina, ela não podia atuar como sempre atuara, dissimular-se em milhões de artefatos, misturar-se ao ruído de fundo (...). Compreendi que se conseguissem purificá-la ainda mais, iriam tomar champanhe, cada qual escreveria dezenas de artigos (...). Como me haviam dito, eu iria presenciar descobertas científicas. (ibid. p. 16).

Relativamente à sua própria inserção e papel no laboratório, Latour afirma que em um breve paper anunciei-Ihes corajosamente que, voltando da África, eu iria agora estudá-los como se eles fossem uma tribo exótica. Começaram a rir, sem acreditar muito no que ouviam (ibid., p. 17). Possivelmente os pesquisadores demonstrassem que, para muitos ainda o é, o trabalho dos epistemólogos em nada modifica sua própria atividade científica.

A observação participante em um laboratório - o "coração da ciência", no dizer de Latour, pode ser reveladora. Nesse sentido, um primeiro limite, ou assunção básica para desvelar as malhas da rede do laboratório (isto é, a complexa relação entre hipótese, observação, testes e experimentação) que é um aspecto inerentemente associado à natureza da ciência é, segundo ele, ignorar ou superar a distinção entre "contexto de descoberta" e "contexto de justificação”. Nas palavras de Latour:

É possível, na verdade, admitir a existência de uma prática de laboratório, de uma competência local, de habilidades tácitas e, ao mesmo tempo, fingir que tudo isso não existe. Basta distinguir o contexto de descoberta, cheio de som e fúria, de desordem e de paixões, e a ele opor o contexto de justificação, calmo e ordenado. (...) em lugar de uma distinção entre os contextos de descoberta e justificação, temos uma gama contínua de transformações, de traduções, de deslocamentos que reatam a "ciência da descoberta" do laboratório de origem com a "ciência justificada" dos outros."(ibid., pp. 32/33, grifo nosso).

Sobre os distintos espaços físicos do laboratório, afirma Latour, são complexos e envolvem dinâmicas, espaços e literaturas distintas. O observador, segundo ele, choca-se com:

(...) uma separação muito clara entre duas zonas do laboratório. Uma (Seção B) está cheia de aparelhos diversos; a outra (Seção A) contém exclusivamente livros, dicionários e artigos. Na seção B o observador constata que a aparelhagem é utilizada em diferentes tarefas: corta-se, cose-se, mistura-se, agita-se, marca-se (...). Na seção A trabalha-se apenas com material escrito: lê-se, escreve-se, bate-se à máquina.' (ibid., p. 37).

(...) artigos de revista cobrem a mesa de um dos "doutores" da Seção A. (...). É como se dois tipos de literatura estivessem justapostos: publicações externas ao laboratório e documentos produzidos no interior do laboratório - esquemas rabiscados com pressa e várias folhas de papel contendo números. (ibid., p. 40).

A leitura atenta de $A$ Vida de Laboratório sugere que outros estudos, em outros laboratórios ou gabinetes de cientistas, podem ser muito úteis para melhor compreendermos a ciência de que somos herdeiros: a ciência contemporânea. Um exemplo, no campo da Física, mas, é claro, com muito menor abrangência pode ser encontrado em Massoni (2009), que buscou lançar um olhar etnográfico a um Laboratório de Supercondutividade e Magnetismo, na UFRGS. As situações, os espaços, as relações, não são em grandes linhas 
diferentes daquelas observadas por Latour, ainda que nos dias atuais a Física seja uma atividade cada vez mais dependente de uma aparelhagem sofisticada, apoiada na construção de modelos teóricos e computacionais cada vez mais complexos e fortemente embasados na matemática, que assume um papel não mais apenas instrumental, mas construtivo, acima de tudo.

A instrumentação, por sua vez, para Latour (Latour e Woolgar, 1997), tem um destaque especial:

Na realidade, o laboratório distingue-se pela configuração particular dos aparelhos que chamamos de inscritores. O que os torna tão importantes é o fato de que nenhum dos fenômenos "aos quais eles se referem" poderia existir sem eles. Sem o bioteste, por exemplo, não há como dizer que uma substância existe." (ibid., p. 61).

Isso também se pode dizer com relação ao laboratório de Física (no estudo já mencionado). Destaca-se, contudo, que em nossa observação os atores eram estudantes de doutorado acompanhados de pesquisadores experientes, em contraste com os profissionais bem remunerados do laboratório de neuroendocrinologia observado por Latour, e não dispunham de material e instrumental ao custo de milhares de dólares/dia como os do Instituto Salk. Ainda assim, foi possível perceber certos traços que poderíamos considerar "comuns" ao quotidiano de distintos laboratórios como, por exemplo, o desenvolvimento de grande quantidade de trabalho debruçado em temas de fronteira; a maioria dos fenômenos observados surge nos instrumentos utilizados e estes são indispensáveis à própria pesquisa, de maneira que todo o trabalho para quando um aparelho quebra ou é substituído por um novo. Nesse sentido, parece haver uma interconexão entre a indústria (fabricante de novos equipamentos) e a ciência (que projeta essas máquinas de que precisa para ir mais fundo no escrutínio da realidade). Outras características comuns são o uso de recursos da eletrônica, de estatística, da modelagem computacional e o foco na produção e publicação de artigos (a taxa de impacto, o número de citações são preocupações constantes entre os pesquisadores). Este é, na verdade, um dos traços que distingue a reputação de diferentes laboratórios. Além disso, foi possível perceber (no caso do laboratório de Física) o quanto é importante dominar, pelos novatos e doutorandos, uma linguagem especializada, linguagem que é compartilhada através de publicações, seminários, encontros e outros eventos científicos.

Para Latour, há outros requisitos que os membros da equipe do laboratório devem ter para que o resultado final seja alcançado. Habilidades e domínios específicos (e. g. manipular aparelhos, testar, controlar) são exigidos:

(...) cada uma das etapas é crucial: caso seja omitida ou mal desempenhada, todo o processo é reduzido a nada. É bem mais difícil obter uma "bela curva" do que uma nuvem caótica de pontos aleatórios, cuja configuração não pode ser repetida. Para evitar essas possibilidades catastróficas, foram realizados esforços no sentido de rotinizar as ações (...). (ibid., p. 67).

Os autores e leitores (como uma tribo, a tribo do laboratório, para Latour) precisam também desenvolver outras habilidades, mais sociológicas: 
verdade do que dizem e do interesse que existe no financiamento de seus projetos. A capacidade de persuasão é tal que eles conseguem convencer os outros, não porque estejam eles próprios convencidos, mas porque estão seguindo uma orientação coerente de interpretação dos dados. Outros estão persuadidos de que não estão persuadidos, de que não há qualquer intermediação intervindo entre o que é dito e a realidade. (ibid., p. 68).

Neste ponto, Latour corrobora o que Kuhn (2003) já havia destacado, de que na gênese dos fatos científicos há muito mais do que dados, curvas e evidências empíricas. Existem aspectos sociológicos, persuasão, interesses, desejo de articular o paradigma.

Para Latour, como aparece na citação acima, há também os que estão persuadidos de que não estão persuadidos e são tão convincentes que no contexto do laboratório é possível deixar de lado as bancadas, a dimensão material e a influência do passado e consagrar exclusivamente os "fatos".

A vivência no laboratório por longo tempo (dois anos) permitiu a Latour afirmar que o fator humano (o pesquisador como elemento de um grupo) e suas qualidades políticas são cruciais tanto para provar um argumento quanto para vencer em habilidade um adversário. As regras de comportamento são pouco visíveis em épocas de atividade normal, mas podem ser vislumbradas em momentos de reorganização "da tribo":

(...) com base em um trabalho de apenas alguns meses, Guillemin conquistou uma situação de destaque, enquanto Burgus e Vale caíam na rotina. Eles continuaram escrevendo artigos sobre os fatores de liberação clássicos, com efeitos de retorno progressivamente descendentes (...).

\begin{abstract}
Esse exemplo de mudança súbita esclarece a importância que as pessoas concedem ao crédito e ao reconhecimento. Guillemin investiu todo o seu crédito em recursos para uma nova área. Usando muito o telefone, contatou vários colegas em outros laboratórios, lançou pesquisas de ampla envergadura, trocou de substâncias, de séruns e produziu novos dados no interior da subdisciplina recém-definida. (...). Outros esforços de pesquisa desenvolvidos pelo grupo foram eclipsados pelo sucesso espetacular das novas substancias. (LATOUR; WOOLGAR, p. 259).
\end{abstract}

Como, então, afirmar que a atividade científica pode estar desvinculada de valores, regras, crenças, culturas?

\title{
A publicação em ciência
}

Os pesquisadores reconhecem, segundo Latour, que a produção de artigos é a finalidade essencial de sua atividade. E para alcançar esse objetivo é preciso uma cadeia intermediária de operações (conferências, reuniões, rascunhos) que começam com o primeiro resultado rabiscado e comunicado com entusiasmo aos colegas $^{4}$ até a publicação do artigo. Esse processo, de alguma forma se assemelha à produção literária, na visão deste epistemólogo. Possivelmente, uma diferença importante em relação à produção literária seja que os artigos contêm um texto tão especializado que faz pouco ou nenhum sentido fora da área, além de, e cada vez mais, terem um número elevado de coautores, dado que atualmente a

${ }^{4}$ Devido à competitividade, às vezes, na prática, os cientistas escondem resultados e perguntas. 
ciência é uma atividade cooperativa, globalizada em alguns casos. Nesse sentido escreve Latour:

É evidente que o crescimento da produção não garante automaticamente uma taxa elevada de retorno, quando consideramos a taxa de impacto como um indicador bruto do efeito de retorno dos custos iniciais de produção de itens de literatura. $O$ fator dominante parece ser mais a frequência de aparecimento dos itens como artigos "padrão". (ibid., p. 74).

Em parte, essas características do contexto de produção científica foram mencionadas por outros filósofos da ciência, mas o diferencial da abordagem de Latour parece estar na vivência que lhe permitiu relatar o processo com tal riqueza de detalhes que seria difícil deles duvidar, embora sua experiência estivesse restrita a laboratórios específicos.

\section{O fato científico}

Sobre a construção do "fato científico", e sobre se é possível eliminar o contexto social e histórico desse processo, Latour afirma que um fato é uma construção social - em seu estudo, o fato [científico] foi: o $\operatorname{TRF}(H)^{5}$ é atualmente um objeto com estrutura molecular perfeitamente definida (...) (ibid., p. 103). É sociológico porque o que se entende por TRF varia no próprio interior da rede formada por aqueles que a ele dedicam sua existência (p. 109); dois laboratórios diferentes o de Guillemin e o de Schally usavam dois nomes diferentes para designar a mesma coisa (TRF, expressando "fator", pela equipe de Guillemin e TRH, expressando "hormônio" na equipe de Schally). Para Latour, a diferença de expressões reflete uma diferença de paradigmas, além de aparecer, nos fragmentos que se seguem, situações claras de competição (entre grupos e dentro dos grupos de pesquisa):

As duas equipes não concordavam que a descoberta havia sido simultânea. Cada qual pretendia ter sido a primeira, acusando a outra de ter recebido os créditos graças às deliberadas ambiguidades dos relatórios de pesquisa. (ibid., p. 109).

Ao todo, quatro equipes trabalharam no isolamento do TRF. Duas delas dirigidas especificamente por Schibuzawa, no Japão, e por Schreiber, na Hungria, abandonaram as pesquisas (...). A equipe de Schally deu início às pesquisas sobre o TRF(H) em 1963. Somente o grupo de Guillemin manteve sua presença nesse campo de pesquisa durante todo o período 1962-1969. (ibid., p. 112).

(...) decisão de se embarcar na pesquisa sobre o TRF levou à postulação da existência de novos fatores discretos, e que esses fatores eram peptídios. Embora na época a ideia de que o cérebro regulava a hipófise fosse um prérequisito para ser neuroendocrinológico, também era possível afirmar que essa regulação devia-se a fatores conhecidos, como a ocitocina e a vasopressina. (ibid., p. 116).

A decisão de buscar a estrutura do TRF $(\mathrm{H})$ também envolveu despesas consideráveis, porque, embora existam, os peptídios só estão disponíveis em quantidades ínfimas (...). A coleta e o tratamento de milhões de hipotálamos representou uma tarefa colossal. (p. 117). 
(...). Pode-se fazer uma ideia da resistência a esse programa quando se compara a estratégia adotada por Guillemin com a de Harris, um dos fundadores da disciplina. Mesmo depois de ter aliciado um químico cuja única função era isolar um outro fator, o LRF, o teste que Harris fez era lento e malconcebido, impedia o químico de filtrar um número de fatores superior a cinco ou oito por mês. Se tivesse deixado o químico trabalhar em seu próprio ritmo, teria obtido frações em quantidades bem maiores (...). Como de hábito, no entanto, o químico teve que se curvar, e o fisiólogo manteve o teste que ele considerava mais interessante. (pp. 117-118).

Como Guillemin estava firmemente resolvido a identificar a sequência do TRF, e como não hesitou em operar urna reformulação total da disciplina centrada nesse objetivo crucial, surgiram novos critérios de confiabilidade. (p. 121).

Entre 1962 e 1966 (inclusive), os dois grupos publicaram 41 artigos ao todo, exclusivamente dedicados às tarefas de isolar e caracterizar o TRF. Eram 24 artigos do grupo de Guillemin e 17 do grupo de Schally. A diferença reflete o fato de que o TRF era o principal programa do grupo de Guillemin, mas não passava de um programa secundário para a equipe de Schally (...). (ibid.,p. 135).

Essa sequência de citações busca ilustrar como Latour percebeu (juntando depoimentos, sequências temporais, tomadas de decisões e fatores diversos) a forma como, finalmente se assume que um enunciado pode ser lido como "contendo" um fato, ou "estando submetido" a um fato. Isso mostra os complexos processos que tornam o fato científico possível.

Sobre a produção de novos "seres" no laboratório ele identificou várias etapas, por exemplo, a fase de testes (no caso, biotestes), o ciclo de purificação, a identificação da substância isolada - no caso do laboratório observado por Latour, o TRF altamente purificado. Assim relata Latour parte desse processo:

\footnotetext{
Por volta de 1968, o TRF havia importado para seu campo inúmeras técnicas provenientes de outras disciplinas - o que pode ser atestado pelo número de citações novas que se encontram nos artigos sobre o TRF (...). A escolha de uma estratégia que consiste em "obter a estrutura a todo preço" engendrou o recurso a técnicas vindas de outras disciplinas (...). De início, os autores apelaram para setores melhor estabelecidos da endocrinologia clássica para obter biotestes confiáveis. Depois, tomaram emprestadas técnicas de purificação da química dos peptídeos. Isso se tornaria relativamente simples depois que Guillemin obteve uma purificação da ordem do milionésimo, em 1966. Em seguida, os atores acumularam uma grande quantidade de extratos de cérebro. Embora difícil, essa tarefa praticamente demandava apenas que se conduzisse uma administração de forma correta e que se acumulasse uma boa dose de paciência. Tal transformação do TRF em plano triplo elevou consideravelmente os padrões de pesquisa. Na verdade, o grau de habilidade química demandado era tão alto que vários grupos atuantes na competição (e que, segundo os termos de Schally, "não tinham peito") esfacelaram-se. (ibid., pp. 141-143).
}

Assim, a produção de um novo "ser" ou "fato científico" não é neutra, ao contrário, depende de movimentos dos atores da comunidade científica que desempenham, individualmente ou coletivamente, diferentes papéis. Às vezes envolvem a própria constituição de um campo disciplinar (no caso, a neuroendocrinologia). De outro lado, há a "construção social" de um mundo que permite aos frutos dessa disciplina "fazer história" com os interesses sociais, econômicos, políticos, industriais. 


\section{A credibilidade científica}

Como já mencionado, um grupo de pesquisa no laboratório possui uma dinâmica tal que para compreendê-la é preciso examinar a história de investimentos e a reconstrução dos currículos dos pesquisadores. Latour pôde perceber que no decorrer dos anos ocorrem mudanças na estrutura do grupo (de forma similar à reorganização de uma tribo, no dizer desse epistemólogo) em que alguns membros lentamente são eliminados passando para a "segunda divisão" enquanto outros ascendem à chefia. As regras desse comportamento, observa ele, não são claras, mas parecem fortemente associadas à credibilidade dos pesquisadores, à projeção externa em função da energia dispendida para captar novos recursos, à ousadia na proposição de novas técnicas, ao número de citações. São vários aspectos que influenciam não apenas a carreira individual, mas a credibilidade e ampliação da produção do próprio laboratório:

Com a credibilidade aumentada, Vale tomou a direção da seção de fisiologia e chegou a ser considerado chefe oficial das operações. Foi assinado um contrato de vários milhões de dólares para que o laboratório se dedicasse, durante cinco anos, a pesquisas sobre diabetes, controle da natalidade e efeitos sobre o sistema nervoso central. O nome de Guillemin desempenhou um papel decisivo para a assinatura do contrato (...). Nesse estágio, o capital de Guillemin (em termos de citações como principal autor) estava em queda, enquanto o de Vale subia muito."(ibid., p. 256).

Como narra Latour, essa época (em 1975) foi quando Guillemin convidou-o para estudar Epistemologia e Biologia o que Ihe permitiu perceber "de que modo os pesquisadores mais antigos deixam o grupo e permitem que os mais novos tomem o poder" (p. 258).

\footnotetext{
Mas em lugar de sair do laboratório para ampliar sua posição no circuito de credibilidade, Guillemin reinvestiu seu tempo e sua energia no trabalho das bancadas. Enfrentando as piadas constantes e o completo ceticismo de seus colegas, ele desenvolveu um trabalho em meio a frascos, colônias, biotestes, à maneira de um jovem pesquisador que acaba de concluir o doutorado. ( $p$. 258).
}

Esse esforço de pesquisa teve profundas repercussões sobre a estrutura do grupo. (...). A nova substância, que em seguida pôde ser produzida em grandes quantidades (...) desempenhava papel importante tanto na farmacologia quanto na química do cérebro (...). Como eram imensos os interesses em jogo, a posição de Guillemin mudou completamente no intervalo de seis meses. Em 1975, ele era um pangaré quase fora do páreo. Em março do ano seguinte, era o membro mais solicitado do grupo (...). (pp. 258-259).

No dizer de Latour, a produção de dados confiáveis é indispensável, mas também é indispensável que o pesquisador tenha iniciativa, capacidade de persuasão e disposição para fazer contatos externos. São meios de ativar o ciclo de credibilidade do laboratório e de colocar em movimento a "economia política" da ciência. Essa dinâmica permite que mais tarde os pesquisadores tirem, eles próprios, proveito e possam afirmar que "tiveram ideias" e com isso conseguiram atrair dinheiro e equipamentos para garantir seu trabalho. Desse ponto de vista, afirma Latour, não estão muito distantes dos homens de negócios ou dos políticos. 
É possível explicar, afirma ele, o comportamento dos pesquisadores em termos de "normas", de "método científico" ou de busca por reconhecimento, mas isso é supérfluo. São tantas as pressões econômicas que cercam o pesquisador, a um só tempo capitalista independente e empregado, que se torna possível prendê-lo solidamente nessa posição, de modo a extrair dele um fato igualmente sólido (ibid., p. 263).

Latour não deixa bem claro o que quer dizer ao falar em pressões econômicas (além de ter a ver com atrair dinheiro e equipamentos para garantir as operações do laboratório), mas, de fato, principalmente na área onde ele se "enculturou" em um laboratório, "uma molécula nova" pode valer milhões de dólares ${ }^{6}$. Nessa área, a pesquisa é, em muitos casos, financiada com vistas à produção de novas "substâncias" que poderão gerar grandes lucros aos financiadores. Por outro lado, em áreas apenas promissoras à geração de lucros, a curto e médio prazo, como a Física, por exemplo, é bem mais difícil obter apoio financeiro. Laboratórios de pesquisa em Física, como por exemplo, de supercondutividade (SANTAROSA; PARISOTO; MOREIRA, 2016) sofrem muito com a falta de recursos financeiros e equipamentos.

Latour vale-se de ideias de Bourdieu (1976) ao mencionar o modelo de "troca científica" (entre pesquisadores, clínicos e indústria), em que há outros domínios em jogo que não a ciência.

\begin{abstract}
O resultado da construção de um fato é que ele parece não ter sido construído. O resultado da persuasão retórica em um campo agonístico [competitivo] é que os participantes ficam convencidos de que não estão bem convencidos. $O$ resultado da materialização é que as pessoas podem jurar que as considerações materiais são apenas um componente menor do "processo de pensamento". O resultado do investimento em credibilidade é que os participantes podem afirmar que a economia e as convicções não intervêm de modo algum na solidez da ciência. Quanto às circunstâncias, elas simplesmente desaparecem dos relatórios, reservados antes à análise política do que a uma apreciação do mundo duro e sólido dos fatos! Embora esse tipo de inversão não seja específico da ciência, ele é tão importante que dedicamos grande parte de nosso argumento para especificar e descrever o momento preciso em que essa inversão se produziu. (ibid., pp. $272 / 273)$
\end{abstract}

Aqui Latour parece resumir sua visão de que a "atividade científica não trata da 'natureza', ela é uma luta renhida para construir uma realidade" e o laboratório é o local de trabalho e o conjunto de forças produtivas que tornam essa construção possível. Ele reafirma que fatos científicos não são descobertos, mas sim construídos socialmente o que enfatiza as negociações sociais na persuasão para a aceitação de uma afirmação como não-controversa; esclarece, assim, por que a inscrição literária, ou seja, a produção de enunciados aos quais é concedido alto valor entre outras afirmações, é tida em tão alta conta no laboratório. "Cada vez que um enunciado é estabilizado, ele é reintroduzido no laboratório (sob a forma de máquina, de inscritor, de saber, de rotina, de pré-

${ }^{6}$ Latour aponta que o laboratório não se ocupa exclusivamente do que se chama de pesquisa fundamental, pois mantém múltiplas relações com clínicos e indústrias, através de patentes (inúmeras substâncias "descobertas" no pagạngrątório (e suas análogas) são patenteadas, são legalmente descritas como tendo sido "inventadas" o que mostra que o estatuto ontológico dos enunciados tem pouca chance de ser regulamentado para sempre; segundo os interesses dominantes, a mesma substância pode receber um novo estatuto) (LATOUR; WOOLGAR, 1997, p. 201). 
requisitos, de dedução, de programa) e aí é utilizado para aumentar a diferença entre diversos enunciados". O processo completa-se quando uma afirmação é reificada em um processo técnico, acondicionada em um instrumento ou produzida como, por exemplo, um pó branco usado por outros grupos de pesquisadores (Lenoir, 2003, p. 42). Mas, afirma Latour, é tão caro colocar em cheque um enunciado reificado que essa se torna uma tarefa impossível.

Na verdade, argumenta ele, a realidade "resiste" à pressão de uma força. Para Latour, a exacerbada discussão que se vê em epistemologia entre realistas e relativistas é, no fundo, fruto da ausência de uma definição adequada de realidade. Só o que não pode ser mudado à vontade, defende ele, é aquilo que conta como real. Mas a postura de Latour e Woolgar não escapa às críticas. Lenoir (2003) concorda que o objetivo do laboratório é criar fenômenos, mas entende que a fragilidade do estudo de Latour e Woolgar está no fato de ser uma análise sociológica dominada pelo enfoque na teoria, isto é, considerar que o objetivo principal do laboratório é a produção de afirmações de alto valor na literatura científica, afirmações não controversas sobre os fatos que acabam aparecendo em livros e manuais, mas atribuem pouco valor à prática e ao caráter multiproposital da experimentação. Pérez Tamayo (2003, p. 274) considera a tese do conhecimento científico como "nada mais" que uma construção social como exagerada. Não há dúvidas, afirma ele, que só se alcança o conhecimento científico na comunidade e que esta precisa apresentá-lo em seminários e congressos, e publicado em artigos e livros. Dessa forma, a ciência surge na, e depende da sociedade. Porém, argumenta, entre isto e que o conhecimento científico está determinado socialmente há uma grande distância. Por exemplo, o trabalho de Pasteur tem enorme valor cultural e constituiu uma imensa contribuição ao avanço da civilização, mas serviu também para estabelecer um método de preparação de vacinas por meio de vírus e germes atenuados. A técnica tem sido eficiente em várias enfermidades e as vacinas têm o mesmo efeito aos cidadãos de Nova York e aos indígenas zapotecas da serra Oaxaca. Indubitavelmente a ciência tem um componente social, mas também tem o compromisso de fazer predições e de checar a correspondência entre os enunciados científicos e o mundo real e esses resultados não pode ser "nada mais" que uma construção social. Slezak (1994) contestou o construtivismo social de Latour por repudiar a noção de "mérito" e porque descrevera ciência como refletindo "interesses e relações de poder entre grupos" nos impediria, por exemplo, de assumir uma posição contrária ao ensino do criacionismo nas escolas.

\section{Antropologia Simétrica}

Através do projeto antropologia simétrica Latour defende a utilização de métodos antropológicos (etnográficos) para estudar com igual rigor e detalhamento tanto o "coração" da ciência e da sociedade, quanto seus aspectos mais marginais; tanto a sociedade "moderna" quanto as demais, as sociedades ditas primitivas ou não modernas.

Ou bem é possível fazer uma antropologia do verdadeiro, assim como do falso, do científico, como do pré-científico, do central, como do periférico, 
antropologia, que nunca passaria de um meio perverso de desprezar os vencidos, dando a impressão de respeitá-los (...).

A noção de simetria forma a base moral deste trabalho. (LATOUR; WOOLGAR, 1997, p. 23).

Para ele, a etnografia da ciência é a metodologia que permite ao observador aproximar-se dos cientistas, contornar seu discurso, familiarizar-se com a produção dos fatos e depois, voltar-se sobre si mesma e explicar o que fazem os pesquisadores com uma linguagem adequada, que não deixe a desejar em relação à linguagem que se quer analisar. Possibilita familiarizar-se com um campo de pesquisa e ao mesmo tempo permanecer independente dele e à distância. Para fazer isto, propõe Latour, não é preciso que o etnógrafo conheça em profundidade os meandros da ciência pesquisada. A ideia de que um bacharel em ciências exatas pode falar com mais intimidade sobre o mundo da pesquisa do que um observador que nele imergiu por longo tempo é um claro preconceito que pode ser derrubado sem o menor pesar (ibid.).

Em Jamais fomos modernos (1994), Latour argumenta que a modernização ${ }^{7}$ (ou a afirmação de que somos modernos e estamos modernizando o planeta) não é um argumento suficientemente forte para justificar uma relação de submissão de outras culturas em relação à nossa cultura (Ocidental). Não é possível pensar, adverte ele, que as outras culturas vivam na confusão entre fatos e valores e que é necessário fazê-las abandonar essa confusão para se modernizarem, ou seja, que seria preciso separar a sua representação do mundo subjetivo, mítico daquilo que é o mundo, o único mundo, o mundo unificado da ciência, da técnica, da economia (...) (LATOUR, 2008, p. 14).

O termo "moderno", afirma ele, possui tantos sentidos quantos forem os pensadores e jornalistas, mas é comum associá-lo a um novo regime, uma aceleração, uma revolução do tempo. Para ele, a palavra estimula uma dicotomia: antigos versus modernos, vencedores versus vencidos. Expressa, assim, uma assimetria. Nessa obra ele analisa historicamente dois casos: Boyle (o cientista criador da bomba a vácuo) e Hobbes (o filósofo-político criador de conceitos como contrato [trocar liberdade por segurança oferecida pelo estado], propriedade, cidadãos, papel do estado), situando-os no seu contexto históricosocial para mostrar como a política deixa "vestígios" na ciência e como esses personagens "brigam" para inventar uma demarcação entre ciência e política (LATOUR, 1994, p. 33).

Busca analisara raiz da distinção entre construção social, de um lado, e verdade científica, de outro, e conclui que a "história dessa distinção" leva-nos às origens da "modernidade". Conclui que essa separação interessava porque permitia à ciência liberar-se das ligações, constrições e exigências próprias da atividade política e, assim, autorizou as relações com outros povos (chineses, polinésios, africanos...). O que nos distinguiria dessas civilizações seria o fato de que eles misturavam suas concepções da natureza com aquelas sobre o modelo

${ }^{7}$ Modernização é um conceito associado à flecha do tempo inventada pelo racionalismo, que separa o passado do pafyturar $\mathbf{A}_{4}$ que coloca de um lado o mundo dos fatos, da evidência natural, das leis da natureza e, de outro, os valores. Esta flecha do tempo define a modernidade, a impressão que exista uma frente de progresso relativamente homogêneo que avança de maneira regular e que distingue sempre melhor os fatos dos valores (LATOUR, 2008, p, 13). 
patriarcal, de família, de organização social etc. Ao passo que nós não, nós fazíamos essa separação (LATOUR, 2008, pp. 43/44).

Dessa análise, Latour afirma ter se dado conta - e buscar expor essa visão de que a ciência moderna é essencialmente um projeto político e econômico.

Mais ainda, defende que é preciso buscar conexões que permitam uma negociação planetária inteligente entre as culturas (LATOUR, 2008, p. 11) como alternativa à ideia da modernização. Trata-se de um projeto, defende ele, capaz de reconhecer as demais culturas de forma mais adequada e, ao mesmo tempo, fazer compreender que ciência, técnica, política, economia, são elementos essenciais e indissociáveis na nossa própria cultura. Assume que precisamos interagir cada vez mais com um número maior de seres híbridos e que, para tal, diplomacia é indispensável. Uma diplomacia que não era necessária quando éramos modernos e queríamos modernizar as demais culturas. Com isso, Latour não sugere que "os modernos" tenham sido ruins, mas, defende ele, fizeram guerras pedagógicas ao tentar ensinar, reeducar (os infiéis, os arcaicos grotescos) por meio deum diálogo imperialista, autoritário, as evidências de um mundo comum, o da natureza, da ciência, da tecnologia.

Em nossos dias, diante da pluralidade dos mundos, argumenta Latour, é preciso ter diplomacia, não para unificar as culturas sob o argumento de que "compartilharmos uma mesma natureza", mas como forma de retomar os temas da ciência e da tecnologia para "transformar" os outros de forma apropriada.

Nesse ponto, Latour alinha-se à epistemologia de Isabelle Stengers (2002), que introduz a noção de cosmopolita no sentido de que diferentes seres (presentes na sociedade moderna) formam um "cosmo" que precisa ser harmonizado. Mas, defende ela, não se deve buscar apressadamente essa unificação (e.g. Bush e Bin Laden não se unificam a partir do compartilhamento de uma mesma natureza, de um mesmo critério de eficácia, de um mesmo Deus; eles estão em desacordo com relação a valores e a elementos muito mais fundamentais que compõem o cosmos). Nessa linha, argumenta, talvez não faça sentido assumir que o mundo é dado pela fria evidência dos fatos objetivos e da natureza (ou somos crentes religiosos ou cientistas).

Ao contrário, Latour (2004) afirma que vivemos um momento de "guerras": guerras culturais, guerras das ciências, guerras contra o terrorismo, contra a pobreza, contra a ignorância e guerras por ignorância. Ele se pergunta: devemos estar em guerra também nós, os estudiosos, os intelectuais? 0 que acontece com o espírito crítico? Como resposta, propõe Latour que está difícil mirar o alvo certo, contudo, como os estrategistas militares precisam, a todo o momento, rever seus planos, armas e estratégias para acompanhar a "atmosfera do tempo", também os estudiosos e intelectuais não estão livres dessas constantes revisões, pois precisam se deparar com novas tarefas, novas ameaças, novas metas. Já foi o tempo em que os intelectuais estiveram na vanguarda, afirma ele, agora estamos despreparados e se ainda quisermos ser confiáveis e promover críticas de vanguarda temos que deixar de lado "as certezas científicas" inerentes à estrutura dos fatos- por exemplo, não há consenso entre os cientistas com relação à questão do aquecimento global, e se o público vier a acreditar que o assunto está resolvido, seu ponto de vista mudará de acordo - e regularmente, se necessário, rever a partir do zero toda a parafernália (ibid., p. 231). Isto não significa que estivemos errados, mas simplesmente que a história muda 
rapidamente e que não há como tratar com "equipamentos velhos" os desafios do presente. A questão nunca foi de ficar longe de fatos, mas mais perto deles, não lutando conta o empirismo, mas ao contrário, renovando o empirismo.

Esse é outro sentido da "antropologia simétrica", a necessidade de repensar nossas sociedades (e consequentemente a ciência e tecnologia que a compõem), de imaginar que um acordo entre culturas não é possível sem que se avalie primeiro o abismo de desacordos entre elas.

\section{Crítica à Epistemologia tradicional}

Como já dito, Latour não endereça suas críticas à ciência. A capacidade dos pesquisadores de produzir enunciados objetivos sobre o mundo natural e social de forma criativa, relativamente honesta, de calibrar acuradamente os experimentos, de dispor de bons instrumentos é indiscutível e é por ele exaltada. Sem a ciência, argumenta, não teríamos a multiplicidade de "seres", propriedades, objetos e fatos novos que, como já citado, fazem com que nossas existências usufruam dessa convivência.

Sua crítica volta-se à epistemologia tradicional, pois, assevera ele, os epistemólogos há décadas tendem a preocupar-se com a distinção entre enunciados científicos e não científicos, a estabelecer o valor relativo de enunciados, mas buscam livrar-se de questões políticas e das interconexões complexas entre ciência e sociedade. Com isso, deixam de lado questões mais fundamentais.

Para ele, o problema não está nos enunciados científicos (natureza, valor e objetividade dos enunciados) ou nos novos "seres" que a ciência pode produzir. As questões fundamentais são outras: podemos construir um mundo comum com esses seres socializados em nosso meio, com conexões que se multiplicam entre esses seres e também conosco? Podemos viver com os embriões de uso terapêutico e contemporaneamente ter nossas famílias? Podemos, ao mesmo tempo, ter os vermes da terra e o desmatamento da floresta? (Latour, 2008, p. 29, tradução nossa).

Esse tipo de questão, defende ele, é que se impõe ao nosso mundo novo e que deveria preocupar os epistemólogos. Para ele, a primeira modernidade esteve caracterizada pelo estado do bem-estar (nesse ponto ele concorda com o sociólogo alemão Ulrich Beck), mas hoje vivemos uma segunda modernidade em que a preocupação central está, ou deveria estar, nas "consequências" (ideia do after effects), com as quais não havia antes preocupação: consequências inesperadas de nossas ações (ibid., p. 31). Propõe ele que estamos atualmente vivendo uma não modernidade (não uma "segunda modernidade"). Vivemos a sociedade das consequências inesperadas, da incerteza, do risco de nossas ações (por exemplo, não dispomos ou não damos voz a especialistas para prever resultados de incêndios, terrorismo, greves...). Isso sugere que precisamos modificar nossas concepções de sociedade, assumir que o conceito de risco não está restrito às companhias de seguro; que o futuro não é mais uma forma de emancipação, mas que se define em termos de vínculos que podemos estabelecer com os novos "seres" que a ciência produz; vínculos que estabelecem um complexo sistema de conexões inesperadas. 
É a isso que ele dirige suas críticas, não ao trabalho sério e comprometido dos cientistas. Defende que é preciso construir a noção de que nem os cientistas, em quem o público em geral confia, poderão controlar as coisas e as complexas conexões em tempo real, em condições de consequências inesperadas. Daí a necessidade de compartilhar (sociedade e cientistas) o que ele chama de protocolos experimentais coletivos. Embora os cientistas estejam mais equipados e sensibilizados frente ao cidadão comum, em tais condições, é preciso avançar para um modelo de "experiência coletiva", adverte ele.

\section{Implicações para educação científica}

Cientes de que as ideias de Latour são polêmicas, consideramos que a análise da evolução de suas ideias pode trazer contribuições à educação. Como adverte Latour, compartilhar esse tipo de preocupação, que não pretende ser apocalíptica, pode ser interessante à educação científica. Uma tentativa de inferir implicações, da visão de Latour, ao ensino de ciências, diante da diversidade e heterogeneidade da escola dos nossos tempos, é aqui tentada: 1) ensinar conceitos científicos aos jovens é indispensável para que compreendam o mundo atual; 2) não é suficiente ensinar ciência clássica (e. g., a mecânica newtoniana), é fundamental, por exemplo, ensinar Física Moderna e Contemporânea, pois é ela quem produz novos "seres", novos fatos científicos, novas propriedades que precisam ser socializadas, como adverte Latour; 3 ) incitar a reflexão sobre as consequências desses novos "seres" e fatos e sobre a forma como são produzidos é fundamental para o despertar da consciência crítica; 4) discutir também os riscos e incertezas do uso das tecnologias, do consumo e seus reflexos no meio ambiente, da forma de vida das sociedades modernas é um caminho interessante para a formação de cidadãos críticos e participativos desse modelo de "experiência coletiva".

Além disso, como advertem Latour e Woolgar (1997), professores e estudantes precisam criar familiaridade com novas tecnologias, com distintas culturas, compreender suas diferenças, respeitar seus valores; compreender a complexidade e limitações que os cientistas têm para prever e controlar eventos inesperados, entender o papel dos modelos no trabalho dos cientistas e que modelos não são a própria realidade. É preciso que os educadores tenham presente que o saber que chega à sala de aula está muito longe do saber que o cientista produz, que modificações e simplificações são necessárias e ocorrem visando transpô-lo ao discurso do professor (RICARDO, 2005).

Para modernizar e adequar o discurso de sala de aula a essas ideias, sem dúvida, a Epistemologia Contemporânea pode ser de muita valia. Por esta razão, entre outras, defendemos que aspectos e discussões epistemológicas explícitas precisam fazer-se presentes na sala de aula e são tão importantes quanto ensinar conceitos científicos, modelos, fórmulas, exercícios. Defendemos que discutir a natureza da ciência deve andar lado a lado ao conteúdo disciplinar se quisermos alcançar uma melhoria no ensino de ciências, de Física em particular. 


\title{
BRUNO LATOUR'S ETHNOGRAPHIC VIEW OF MODERN SCIENCE AND THE SYMMETRIC ANTHROPOLOGY
}

\begin{abstract}
The purpose of this text is to present Bruno Latour's ideas about the nature of science originated from his immersion in an advanced scientific laboratory, at that time, in which he investigated science in its practice, using ethnographic methods. With this, he turned away from the traditional epistemology, which he criticized as being too much concerned with the distinction between scientific and nonscientific statements as well as with the value and objectivity of these distinct statements. With his study, he showed that the conditions of production were not independent of the products of science and that the "beings", properties, and objects that science could produce with extreme competence, which highly modified and are still modifying life in modern society, must be socialized under new bases and perspectives.
\end{abstract}

KEYWORDS: science ethnography, Bruno Latour, laboratory life, symmetric anthropology. 


\section{REFERÊNCIAS}

BLOOR, D. Conhecimento e imaginário social, São Paulo: Editora UNESP, 2009.

FLECK, L. Gênese e desenvolvimento de um fato científico.Belo Horizonte: Fabrefactum Editora, 2010 (publicação original em lingua inglesa: The genesis and development of a scientific fact, Chicago: University of Chicago Press, 1979).

KROPF, S. P.; FERREIRA, O. F. A prática da ciência, uma etnografia no laboratório. Livros \& Redes, pp. 589-597, $1998 . \quad$ Disponível em:https://www.yumpu.com/pt/document/view/12813152/a-pratica-da-cienciauma-etnografia-no-laboratorio-scielo. Acesso em 29/11/2015.

KUHN, T. A estrutura das revoluções científicas. São Paulo: Editora Perspectiva. 8 ed., 2003

LATOUR, B. Jamais fomos modernos, Rio de Janeiro: Editora 34, 1994.

Why has critique run out of steam? From matters of fact to matters of concern. Critical Inquiry, vol. 30, n. 2, pp. 225-248, 2004.

Disinventare la Modernità:conversazioni com François Ewald. Milão: Elèuthera Edizioni, 2008.

LATOUR, B.; WOOLGAR, S. A Vida de Laboratório: a produção dos fatos científicos. Rio de Janeiro: Relume Dumara, 1997.

LENOIR, T. Instituindo a Ciência: a produção cultural das disciplinas científicas. São Leopoldo (RS): Editora UNISINOS, 2003.

LYRA, E. Entrevista concedida ao Portal PUC-Rio Digital, 2010. Disponível em:http://puc-riodigital.com.puc-rio.br/Jornal/Cultura/\%22Popper-descreve-ocientista-como-um-sujeito-ideal\%22-7578.html\#.VLkBidLF8a9. Acesso em 04/03/2015.

MASSONI, N.T. Laboratório de Supercondutividade e Magnetismo: um enfoque epistemológico.Caderno Brasileiro de Ensino de Física, v. 26, n. 2, pp. 237-272, 2009. 
RICARDO, E. C. Competências, interdisciplinaridade e contextualização: dos Parâmetros Curriculares a uma compreensão para o ensino de ciências. Tese de Doutorado. Programa de Pós-Graduação em Educação Científica e Tecnológica, UFSC, Florianópolis, SC, 2005.

SANTAROSA, M. C.; PARISOTO, M. F. e MOREIRA, M. A. Observações em um laboratório de supercondutividade e magnetismo: aspectos metodológicos e epistemológicos. Instituto de Física, UFRGS, original ainda não publicado, 2016.

SLEZAK, P. Sociology of scientific knowledge and scientific education: part 1. Science \& Education, vol. 3, n. 2, pp. 265-294, 1994.

STENGERS, I. A invenção das ciências modernas.São Paulo: Editora 34, 2002.

WATSON, J. D. La double hélice. Paris: Laffont, 1968.

Recebido: 2016-02-26

Aprovado: 2017-07-31

DOI: $10.3895 /$ rbect.v10n3.3776

Como citar:

MASSONI, N. T.; MOREIRA, M. A. A visão etnográfica de Bruno Latour da ciência moderna e a antropologia

simétrica. Revista Brasileira de Ensino de Ciência e Tecnologia, v. 10, n. 3, 2017. Disponível em:

<https://revistas.utfpr.edu.br/rbect/article/view/3776>. Acesso em: xxx.

Correspondência:

Neusa Teresinha Massoni - neusa.massoni@ufrgs.br

Direito autoral: Este artigo está licenciado sob os termos da Licença Creative Commons-Atribuição 4.0

Internacional.

(c) (i) 